\title{
High-Speed Railway Passenger Station Based on Contingency Theory Promotes the Construction of Flexible Organization for the Integration of Industry and Service Industry
}

\author{
Chao Yin ${ }^{1 *}$, Zejian Zhang ${ }^{2}$ \\ ${ }^{1}$ School of Business Administration, Shandong Women's University, Jinan, Shandong, China \\ ${ }^{2}$ Hubei Institute of Logistics Technology, Xiangyang, Hubei, China \\ *Corresponding Author.
}

\begin{abstract}
Firstly, the paper discusses the theoretical progress of contingency theory in organization construction, which lays a theoretical foundation for the research of flexible organization construction of high-speed railway passenger stations. Then, based on the contingency conceptual framework proposed by Lucence, the conceptual framework of flexible organization construction of high-speed railway passenger station is constructed in combination with the operational characteristics and operating environment of high-speed railway passenger station. This paper explains the connotation of flexible organization construction of high-speed railway station. On this basis, the paper puts forward the idea of flexible organization construction of high-speed railway passenger station. Finally, five supporting measures for the construction of flexible organization of high-speed railway station are put forward. These studies provide theoretical guidance and construction ideas for flexible organization construction of high-speed railway stations in response to passenger flow fluctuation; the main strategy is to give priority to the introduction and cultivation of producer services in developed cities.
\end{abstract}

Keywords: Flexible Organization, Contingency Theory, Flexible Culture, Collaborative Management, Passenger Station, High-Speed Railway, Industry

\section{Introduction}

China's high-speed railway is in the period of rapid development. As an important transportation hub at the intersection of the road network, the operation efficiency and service quality of high-speed railway passenger station will have an important impact on the development of high-speed railway. As an important support for its daily operation, the organization and construction of high-speed railway passenger station has become the top priority in the management of high-speed railway passenger station. With the rapid development of high-speed railway, the uncertainty of the environment in which the high-speed railway passenger station is located is higher, and the fluctuation of passenger flow caused by it is more obvious, which has a negative impact on the operation efficiency of the high-speed railway passenger station. The traditional rigid organization of high-speed railway station cannot meet the requirements of highly uncertain environment under dynamic competition conditions. Contingency organization theory holds that the internal organization of an enterprise should be combined with its external environment, and the two must be properly coordinated before the organization can be effective. Jain et al. (2020) study the role of environmental management system and organizational flexibility in oil and gas sector. The study reveals that organizations leverage EMS to achieve CE performance, and flexible organizations compared with rigid ones are more effective in dealing with coercive pressures by leveraging EMS. These insights may help policymakers to formulate regulatory framework judiciously that encourages firms to adopt EMS in making their operations environmentally sustainable [1]. Therefore, in order to adapt to the impact of passenger flow fluctuations, high-speed railway passenger stations need to maintain moderate flexibility in organizational construction to achieve organizational goals and ensure operational efficiency.

In the past five years, scholars at home and abroad have conducted a large number of researches on organizational

ISSN: 0010-8189

(C) CONVERTER 2020

www.converter-magazine.info 
flexibility. The research directions are mainly divided into three categories. The first category is the empirical research on the relationship between organizational flexibility and enterprise performance and innovation. Gutierrez-Gutierrez et al. (2020) analyze the role of Dynamic Capability (DC) in Six Sigma management and a flexible organization, the study shows that there is indeed a significant relationship between Six Sigma implementation and DCS. In addition, the researchers also found a relationship between flexible management and strategic operations [2]. Zhao et al. (2020) analyzed the mechanism of organizational flexibility improving service innovation performance by enhancing the dynamic service innovation capability of enterprises, and constructed a theoretical model reflecting the relationship between the above concepts. The results show that organizational flexibility has a positive impact on service innovation performance, and dynamic service innovation capability and market dynamics play a mediating and moderating role in the relationship between the two, respectively [3]. Wang et al. (2017) from the perspective of organization, this paper studies the influence of organizational improvisation on competitive advantage, and introduces environmental uncertainty and organizational flexibility to moderate the study. The results show that organizational flexibility has a significant positive moderating effect on the relationship between the four dimensions of organizational improvisation and competitive advantage respectively, and it has a more significant moderating effect on the relationship between immediate response and intentional creation and competitive advantage [4]. These studies show that the construction of flexible organization is of great significance to the improvement of enterprise performance. The second category is the research on the influencing factors of organizational flexibility. Linda (2015) thought build an innovative and flexible organization that can respond rapidly to changing circumstances to retain competitive advantage and keep employees engaged [5]. Xhafa et al. (2017) thought today s competitive world requires organizations to con-stantly change and adapt themselves to new technologies in order to hold the competitive edge among competitors. This requires them to develop applications by underpinning the recent advances in technology, platforms, architecture and their ability to manage them effectively. The aim is to enable the organizations to become more flexible (adaptive, responsive and agile) at the level of strategy, structure, systems, etc. [6]. These studies provide a good focal point for improving the flexibility of enterprises. The third category is the research on the promotion strategy of enterprise flexibility. Fewell and Jennifer (2015) research social insect populations that live in groups show that social interaction and self-organizing development can achieve good evolutionary results in the complex physical structure of habitation constructed by the group organization; Flexible organization and management standards; Able to reach reasonable consensus in collective decision making [7]. Telha et al. (2015) thought organizations work in a constantly changing environment. It is extremely important that they adapt to these changes, in order to get the best performance and advantage of its available resources [8]. Zhang (2020) adopted contingency management theory, flexible organization theory, risk management theory and other scientific management theories as well as critical chain technology, system management method and overall analysis method A variety of research methods, such as fault tree analysis, are used to strengthen process control and risk management, and build a space model project management system oriented to the whole life cycle of products [9]. These studies provide good ideas and guidance for the construction of flexible organization.

Contingency theory, as a mature management theory, has been developed for several decades. Scholars have accumulated a lot of experience in the application of Contingency Theory in organization construction in all walks of life. Shen and Jiang (2019) based on the dynamic capability perspective and institutional theory, this paper explores the factors that affect the performance of NPD. The results show that a high degree of strategic flexibility can promote the firm's new product performance; a high level of organizational legitimacy and government support are beneficial to enhance the role of strategic flexibility in promoting the performance of new products [10]. Dai et al. (2018) studied two types of effects from the outside. They believed that strategic flexibility is a vital capability for new ventures to update their strategies in a timely manner [11]. Yang (2015) found that strategic flexibility has a positive effect on the adoption of green management practices, and institutional support moderates this relationship by strengthening the positive effect [12].Liu et al.(2018) selected Haier Group as the sample enterprise, and conducts an exploratory longitudinal case study to reveal how the enterprise activates the substitution and complementary effect of dual human resource flexibility (employment flexibility and skill flexibility), improves the organizational performance, and creates the dynamic evolution process of flexible organization through the 
multiple strategic matching of human resource management[13].

Therefore, the research of scholars has provided a lot of reference basis for the construction of flexible organization. However, because high-speed railway is still an innovative and developing industry in the world, there are still few researches on the construction of flexible organization of high-speed railway passenger terminal station and the construction of flexible organization of high-speed railway passenger stations has a certain necessity. At the same time, the rich research results of contingency theory also provide abundant theoretical guidance for the writing of the thesis, so that the research has certain feasibility.

\section{Connotation of Flexible Organization Construction of High-Speed Railway Passenger Transport Hub from the Perspective of Contingency Theory}

\subsection{Contingency Theory and Organization Construction}

Contingency theory is based on the system view, which regards an organization as an open system that develops through continuous interaction with its environment. The management system constituted by the management activities of the organization must be considered in the context of the whole open system. Due to the complexity and dynamic characteristics of the environment in which modern organizations are located and the organizational system itself, it is impossible to have some general principles, principles and methods applicable to all situations and organizations. Instead, appropriate management methods can only be selected according to various specific conditions to make a random response [14].

Contingency theory in organizational structure is an important branch of Contingency Theory. Woodward, the pioneer of contingency theory, first proposed that the effective organizational structure and management system are determined by the technical characteristics of an enterprise. On the basis of Woodward, Burns and Stoker further expand the scope of their research to include the external environment of the organization, including such factors as the technical and economic conditions of the enterprise product market and scientific development. They clearly pointed out that organizational structure and management methods are mainly dependent on certain environmental factors, in particular the speed of technological development and the speed of market change. For organizations with different external environments, different organizational structures and management modes should be adopted in accordance with their external environments. On the basis of their own research, Burns and Stoker divide the organizational structure of enterprises and their corresponding management styles into two types. One is the mechanical organization, which mainly adopts the organizational structure with clear division of labor, clear hierarchy and obvious hierarchy, and implements functional specialization and centralized management. It is suitable for enterprises with relatively stable or simple environment. The second type is organized organization with flexible organizational structure, sensitive response to external changes, and emphasis on horizontal collaboration and information communication among colleagues. It is suitable for enterprises with uncertain, complex and changeable environment [15]. This also provides the initial theoretical basis and thinking for the construction of enterprise flexible organization. Later, Erik Trist absorbed the viewpoint of the behavioral school crowd relationship theory, and noticed the social psychology of organization members and the influence of informal organization on management.

By integrating all the contingency theories, Fred Luthans proposed a theoretical framework with strong explanatory power, which made a key contribution to the standardization and systematization of contingency management theory. It consists of three main parts: environment variables management variables and the contingency relationship between them. Luthans combined all three into the following matrix diagram. 


\section{THEN}

Manage

Variables

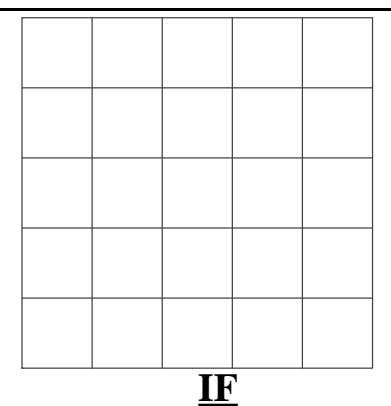

Environment

Variables

Fig. 1: The conceptual framework of contingency in Lucence

The horizontal axis represents the environmental change (IF), the vertical axis represents the management variable (THEN), and each small square represents the contingency management of a specific "IF-THEN". According to Luthans, there is a "IF_ SO" contingency relationship between environmental variables and management variables, which is essentially a functional relationship between environment as independent variable and management as dependent variable [16]. Specifically, it can be expressed as, "IF" a certain environmental situation occurs or exists, it is necessary to adopt some management ideas and methods to better achieve organizational goals. In this paper, The Contingency Conceptual Framework of Luthans is extended to the organization construction, that is, "IF" there is a certain environmental situation, it is necessary to adopt some corresponding organizational optimization and improvement methods, this makes the operation of the organization more efficient and achieve the organizational goals. Namely, the construction and adjustment of organizational structure should be flexibly selected according to the specific circumstances of the external environment and internal conditions of the organization, and adapt to the changes of the development of the environment and conditions.

\subsection{Conceptual Framework for Flexible Organization Construction of High-Speed Railway Stations}

With the rapid development of high-speed railway, the complexity and dynamics of the environment where high-speed railway passenger stations are located are gradually enhanced. The impact of abnormal fluctuation of passenger flow on the organizational construction of high-speed rail passenger's stations is also increasing. The organizational optimization of high-speed railway passenger stations has become the focus of management. At the present stage, the organizational structure of high-speed rail hub station still belongs to the traditional bureaucratic system, and its coordination ability is poor. Moreover, due to the numerous management levels, it is difficult to coordinate between the higher and lower levels. In addition, the traditional rigid organization information flow is not smooth, and the characteristics of slow response to the market do not meet the strong requirements of competitive interaction under dynamic competition conditions. It is very necessary for the flexible organization construction of high-speed railway station to adapt to the rapid changes of external environment and internal conditions. Therefore, based on the contingency conceptual framework proposed by Luthans and in combination with the operational characteristics and environment of high-speed railway passenger stations, the author constructs the conceptual framework of flexible organization construction of high-speed rail hub station. To find out the flexible organization construction method for high-speed railway passenger stations, as shown in Figure 2. 


\begin{tabular}{|c|c|c|c|}
\hline \multicolumn{2}{|c|}{$\begin{array}{c}\text { Environment } \\
\text { Variables }\end{array}$} & $\begin{array}{l}\text { anage } \\
\text { riables }\end{array}$ & $\begin{array}{l}\text { Organizational } \\
\text { Building }\end{array}$ \\
\hline $\begin{array}{l}\text { Developmental } \\
\text { Growth }\end{array}$ & $\begin{array}{l}\text { Development Competition } \\
\text { Structure Upgrade; Economic } \\
\text { Consumption Concept Habits }\end{array}$ & $\begin{array}{c}\text { Group } \\
\text { Ascension }\end{array}$ & $\begin{array}{l}\text { Conventional } \\
\text { Organization }\end{array}$ \\
\hline $\begin{array}{c}\text { Regular } \\
\text { Fluctuation }\end{array}$ & $\begin{array}{c}\text { Weekend Holiday Summer } \\
\text { Travel; Growth Network } \\
\text { Mapping Changes }\end{array}$ & $\begin{array}{c}\text { Scientific } \\
\text { Forecasting }\end{array}$ & $\begin{array}{c}\text { Flexible } \\
\text { Organization }\end{array}$ \\
\hline $\begin{array}{c}\text { Abrupt } \\
\text { Fluctuation }\end{array}$ & $\begin{array}{c}\text { Storm, Heavy Snow and Fog; } \\
\text { Effects of Adverse Events at } \\
\text { High Speed in Aviation }\end{array}$ & $\begin{array}{l}\text { Advance } \\
\text { Warning }\end{array}$ & \multirow[b]{2}{*}{$\begin{array}{c}\text { Emergency } \\
\text { Management }\end{array}$} \\
\hline $\begin{array}{c}\text { Sudden } \\
\text { Fluctuation }\end{array}$ & $\begin{array}{l}\text { Delayed Vehicle Failure } \\
\text { Accident; Congestion } \\
\text { Backlog of Violent Station }\end{array}$ & $\begin{array}{l}\text { Emergency } \\
\text { Disposal }\end{array}$ & \\
\hline $\begin{array}{l}\text { Synergistic } \\
\text { Effect }\end{array}$ & $\begin{array}{l}\text { Subway Bus Rental Private } \\
\text { Cars; Catering Business } \\
\text { Passenger Disputes, Etc. }\end{array}$ & $\begin{array}{c}\text { Organization } \\
\text { Moderate }\end{array}$ & $\begin{array}{l}\text { Coordinated } \\
\text { Management }\end{array}$ \\
\hline
\end{tabular}

Fig. 2: Conceptual framework of flexible organization construction of high-speed railway stations

2.2.1 Routine organization and construction guarantee the stable operation of the station

With the sustained development of national and regional economy, the improvement of people's consumption level, the change of consumption concept and the optimization of high-speed railway services, the passenger flow of high-speed railway stations has witnessed a stable and developmental growth. At this time, the regular organizational construction and improvement of high-speed railway passenger station can ensure the stable operation of the station and guarantee the passenger service quality and service level.

2.2.2 The construction of flexible organization should deal with the abnormal fluctuation of ridership The fluctuation of ridership in high-speed railway station can be divided into three situations:

First, it fluctuates regularly. During peak passenger flow periods such as weekends, legal holidays, summer holidays and Spring Festival travel, passenger flow of high-speed railway stations will increase greatly, while the road bureau will adjust the map and change the channel, which will also cause the fluctuation of passenger flow. Such passenger flow fluctuation has a certain regularity, which can be known in advance through scientific prediction.

Second, it fluctuates abruptly. The occurrence of aviation high speed adverse events will indirectly promote the abnormal growth of railway passenger flow, while extreme weather such as storm, rainstorm, snow and fog will have a serious impact on the train operation, resulting in the abnormal situation of train delay and passenger backlog. Especially for Beijing South Railway Station, such as the starting station, terminal station and hub station, the fluctuation of passenger flow will be more obvious and more violent. With the increasing speed of high-speed railway, once a train breaks down or is delayed for other reasons, it is easy to cause the delay of all the trains in the whole direction of travel, thus forming a large area of delay. The origin, terminal and hub stations will be faced with the situation that passengers of delayed trains cannot travel and transfer in time or all passengers of delayed trains arrive almost at the same time at the same time. The passenger flow will surge in an instant, which seriously disturbs the order of the station, destroys the environment of the station, and impacts the management and service of the station. In the face of such abrupt passenger flow fluctuations, high-speed railway stations need to do a good job of early warning in order to be able to respond in time.

Third, it fluctuates suddenly. The occurrence of emergency incidents such as train overloading failure and station 
fire and terror will also cause a large area of backlog of passengers in high-speed railway stations and disorder, and even the safety of passengers' lives and property may be seriously threatened. This kind of sudden fluctuation of passenger flow caused by emergencies must be actively dealt with by the station to take emergency action.

The above three passenger flow fluctuations will increase the work intensity of employees, which poses a great challenge to the production organization standard management and the ability of employees. Therefore, it is urgent to increase the flexibility of the organization and the flexibility of the posts, so as to ensure that the station can organize enough teams in a short period of time to actively deal with the fluctuation of passenger flow and the need for a large number of manpower.

\subsubsection{Peripheral organizations achieve collaborative management}

The modern high-speed railway station has assumed the role of the city's comprehensive transportation transfer hub and modern passenger transport center with the intersection of various transportation modes. It integrates various transportation modes, such as subway, bus, rental and private car, as well as various service industries, such as commercial hotels and tourism. On the one hand, it can provide more convenient and comprehensive travel services for passengers. On the other hand, the cooperative management of the station is also put forward higher requirements. Once the abnormal situation occurs to the subway and bus merchants and other external organizations, it will also cause the abnormal fluctuation of the passenger flow in the high-speed railway station, which will bring great challenges to the management of the station.

The abnormal fluctuation of passenger flow and unstable external environment of high-speed railway station may lead to the instantaneous increase of passenger flow, which increases the work tasks of each employee, disrupts the normal production and operation order, and brings no small impact to the routine management of high-speed railway station. Therefore, in order to better cope with the surging passenger flow and unstable external environment, it is very essential to increase the flexibility of the high-speed railway station organization, so as to maintain the normal operation of the high-speed railway station.

\subsection{The Idea of Flexible Organization Construction of High-Speed Railway Station}

On the construction of enterprise flexible organization, many domestic scholars have done related research, which has a very good guiding significance. Wright and Snell (1998) presented a framework for studying the concepts of fit and flexibility in the field of strategic human resource management [17]. Verdu-Jover et al. (2017) proposed two determinants of adaptive organizational culture; these studies are helpful to understand how organizational culture evolves and how to promote the innovation of enterprise products and services [18].Zhou (2020) Based on the five economic effects of high-speed railway that affect the industrial orientation, the main strategy for the high-speed railway new town areas with the combination of "economic linkage region + manufacturing cluster area + high-speed railway hub" should be to give priority to the introduction and cultivation of producer services in developed cities [19]. Allen and Imrie (2018) mentioned flexible and diverse forms of organization may result in a variety of challenging and autonomous organizational work [20]. Thus it can be seen that the construction of flexible organization can be achieved by breaking the structure between departments that hinders the construction of task team rotation training and other methods.

Under the guidance of the conceptual framework of flexible organization construction of high-speed railway passenger stations and in combination with the characteristics of operation and management of high-speed railway passenger stations, this paper argues that the construction of flexible organization of high-speed railway passenger stations needs to break the structural barriers between departments, and the organizational construction form of emergency transfer of idle personnel to provide cross-department support during the peak of passenger flow. The construction of flexible organization of high-speed railway passenger stations is guaranteed by skill training and personnel training and post rotation under normal conditions, which is a good method to solve the shortage of personnel in the case of abnormal fluctuation of passenger flow. The construction idea is shown in Figure 3.

ISSN: 0010-8189 


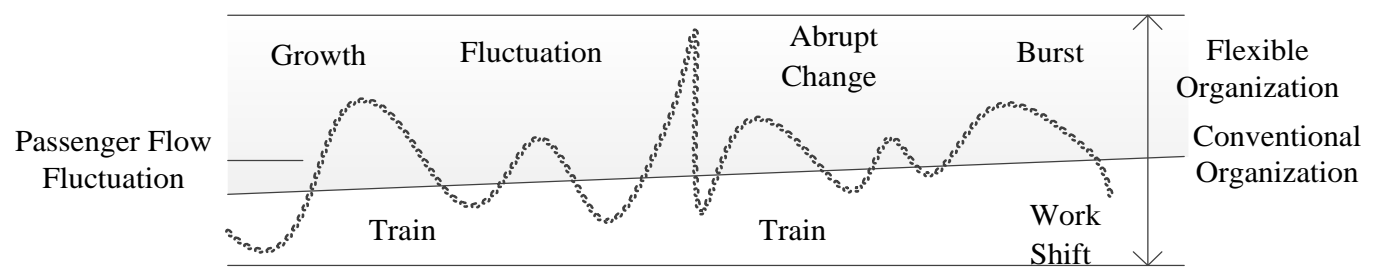

Fig. 3: Schematic diagram of flexible organization construction of high-speed railway station

High-speed rail station of the flexible organization and management is based on the conventional organization build post configuration, is in the peak passenger flow, the staff work tasks of emergency scheduling dwell less department or workshop staff help workloads of a line homework personnel to carry on the production operation, to cope with the huge traffic, make up the homework personnel gap, alleviate the working pressure of frontline staff. In the period of stable passenger flow, personnel training and staff rotation need to be organized to ensure that employees can master multiple skills and adapt to new jobs well in emergency dispatching. In addition, strengthening the scientific standardization and institutionalization of flexible organizations, including flexible organizations in organization construction and talent training, and including flexible work of employees in daily management and performance appraisal are also the key points to be optimized for flexible organization management.

\section{The Flexible Organization Construction Measures of High-Speed Railway Stations}

\subsection{Scientific Planning of Flexible Organization Construction}

The modern high-speed railway station is a large comprehensive transportation hub that integrates municipal transportation facilities such as general speed railway, high-speed railway urban rail transit and bus rental. The daily passenger throughput is huge, and the fluctuation of passenger flow is also very severe. During the rush hour, there is often a huge gap of personnel. To cope with the impact of passenger traffic, high-speed railway stations need to carry out flexible scheduling and scientific planning on the basic organizational structure of bureaucratic system, as shown in Figure 4. 


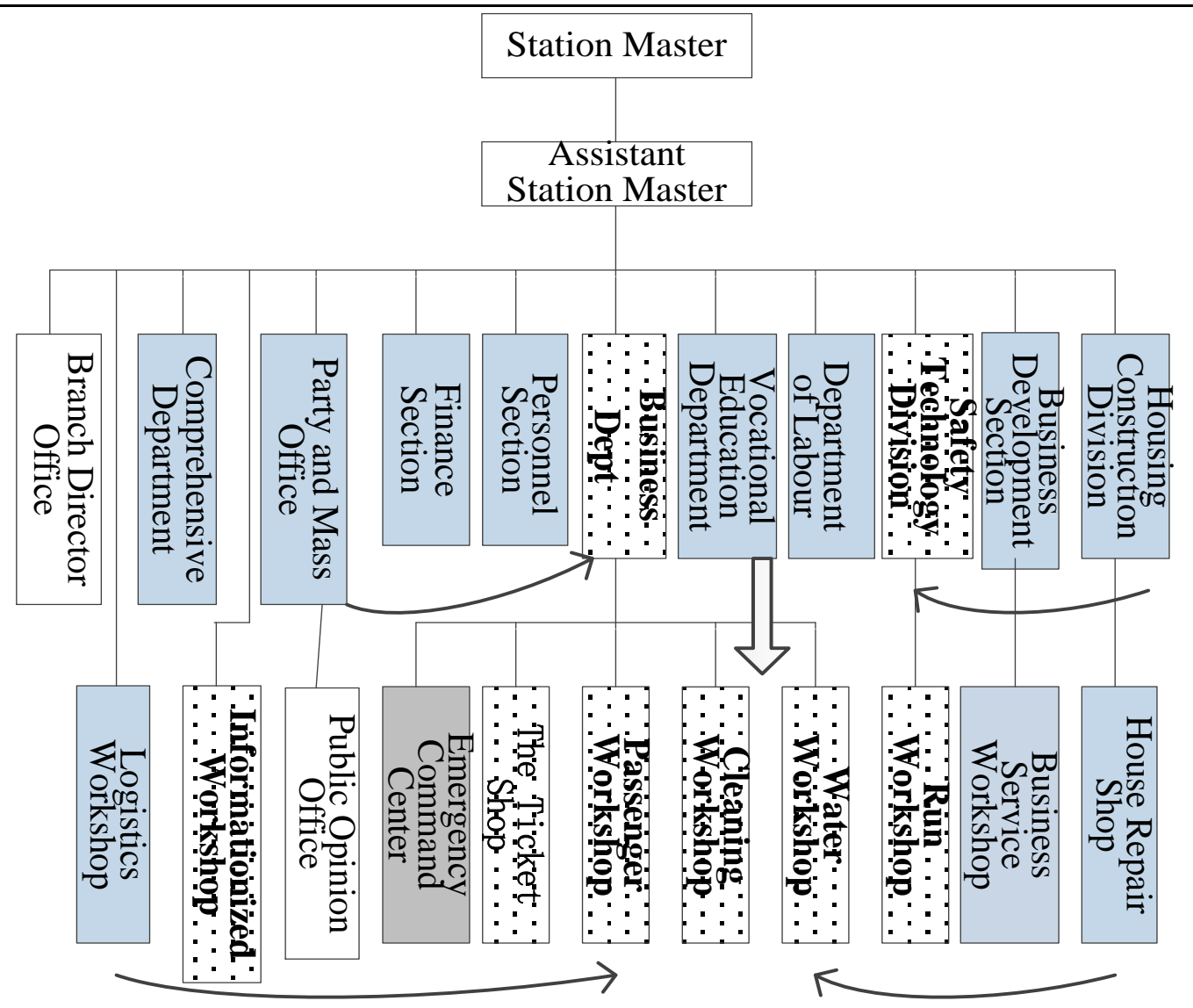

Fig. 4: Personnel deployment diagram of flexible organization construction of high-speed railway station

The organization can be divided into different flexible levels according to the emergency intensity: In case of abnormal fluctuation of passenger flow, the emergency command center is the center for information collection and transmission, as well as the center for command decision-making, management and coordination, and its personnel allocation must be guaranteed to be sufficient. The passenger transport workshop, ticket selling workshop, water workshop, run workshop is very heavy during the rush hour, and the personnel gap is large. As its direct management and guidance department, the work intensity of the business department is also great. Due to the different nature of business, the financial department, personnel department, vocational education department, logistics department and other departments will not increase the workload due to the surge of passenger flow, and the personnel is relatively sufficient. Therefore, the department can be assigned to help the operation, horizontally by logistics workshop and other work tasks relatively few workshops to assign fixed staff to support the passenger shop ticket shop and other operations, by the work tasks relatively few departments to support the operations of the business department and security planning department; The departments with relatively sufficient personnel vertically supplement the personnel gap of the front-line workshop downward to form a reasonable allocation of personnel.

\subsection{Carry out Post Echelon Construction}

When the high-speed railway station is in the peak period of passenger flow, the financial department, personnel department, vocational education department, logistics workshop and other departments with relatively little business support the front-line operations of the ticketing workshop and passenger workshop. At this time, this part of emergency support personnel can be classified as the second echelon staff of the support department, and business training can be carried out according to the post requirements of the support department, and the second echelon staff and the post of the emergency support department can be fixed and standardized. Through the

ISSN: 0010-8189 
construction of post echelon, the scheduling of staff is institutionalized. In case of abnormal fluctuation of passenger flow, the corresponding staff of the second echelon of the department will be selected to work directly, which improves the efficiency of the organization to deal with changes.

\subsection{Implement a Cross-Training Post Rotation Mechanism}

Most of the staff training inside the high-speed railway station adopts the mentoring system, and the teachers of the department are responsible for teaching the staff various business skills. It is suggested to implement the multi-tutorial system, that is, to help employees to mentor in other departments and other positions, so that employees can master 1-2 new job skills on the basis of their own proficiency in the work, so that they can better and faster adapt to the new job in an emergency.

The job rotation system is based on cross-training of employees and provides opportunities for employees to move between different jobs after they have enriched their working skills. This is not only a means to cultivate versatile talents for the station, but more importantly, it can back up the technology and resources of the station and reduce the dependence of the station on specific employees in the process of operation and management. In this way, when the passenger flow fluctuates and the personnel allocation is insufficient, the reserve force in the station staff team can also take the place of the post immediately.

On the basis of completing the work tasks of this post, the station staffs for emergency support are transferred to the emergency post for operation, and their workload has been greatly increased relative to their original post requirements. Therefore, it is necessary to take the workload and performance of employees in emergency operations as an important indicator of performance evaluation and an important basis for rewards, so as to improve the sense of fairness and satisfaction of employees and improve their enthusiasm for work.

\subsection{Cultivate Flexible Culture and Construct Learning Organization}

With the enhancement of employees' democratic awareness, the old rigid management culture has great limitations. The construction of flexible culture becomes the guarantee of flexible organization construction of high-speed railway stations. The cultivation of flexible culture requires the managers of high-speed railway stations to change the management concept, maintain more openness and tolerance encourage individual innovation and organizational learning, and prepare contingency space for the changes that are coming at any time.

To construct a learning organization, the first thing to do is to create a learning leader, so as to play a good demonstration role in the station and create a strong learning atmosphere. Second, we should create a learning team, encourage employees to create learning interest groups, cultivate common interests of employees, and promote knowledge sharing. Through the construction of a learning organization, employees are guided to constantly update their business knowledge and improve their business quality, so as to actively respond to daily work and emergencies.

3.5 Strengthen the Connection with the External and to Achieve Collaborative Management

ISSN: 0010-8189 


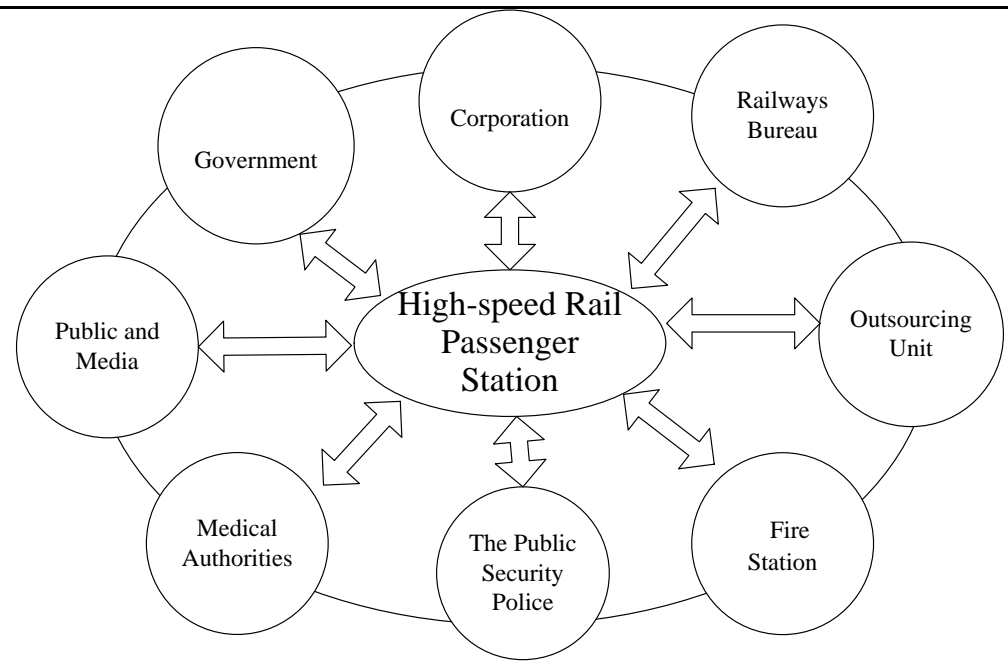

Fig. 5: External organization diagram of high-speed railway station

Enterprise organization is an open system; the optimization of organizational structure needs to interact with internal and external contingent factors. The construction of flexible organization of high-speed railway passenger stations also needs to strengthen information exchange and organizational contact with external organizations, as shown in Figure 5. Strengthen communication with the Road Bureau, help the station to create more opportunities for learning, communication and work communication, and provide positive help for the career development of employees. Information sharing with government departments helps stations actively obtain relevant operation information and support. Increase the publicity of information to the public and the media to ensure the public image of the station. Through information sharing with all kinds of external organizations, we can achieve collaborative management, adapt to the changing development environment and fierce competition situation with the help of external organizations, and improve organizational efficiency.

\section{Conclusions}

As an open system, the organizational structure and manpower allocation of high-speed railway passenger station require to be combined with the external environment and its own strategy. The construction of flexible organization can be completed through the measures of flexible personnel scheduling and post rotation system, cross-training and the construction of learning organization, so as to help high-speed railway stations actively cope with the impact of abnormal passenger flow fluctuations. In addition, information sharing and resource sharing with external organizations are the external support for the construction of flexible organizations. Only by properly handling the division of responsibilities between internal and external organizations and strengthening the connection between them, can high-speed railway stations be ensured to respond quickly to the changes of external environment. The construction of flexible organization is a management focus that requires the combination of internal and external forces and the reasonable allocation of internal personnel and scientific planning. it is very important for high-speed railway stations to gain market competitive advantages.

\section{Acknowledgements}

The research process and results of the thesis have been supported by Shandong Women's University, China.

\section{Funding}

The authors acknowledge the Key R \& D project of Hubei Province: A public service platform for quality traceability of agricultural products supply chain based on block chain (Grant: 2020BBB093), and National Social Science research Fund: Research on performance Improvement of Public Brand Construction of Regional Agricultural Products in China (Grant: 17BJY104).

ISSN: 0010-8189 


\section{References}

[1] Jain N K, Panda A, Choudhary P. Institutional pressures and circular economy performance: The role of environmental management system and organizational flexibility in oil and gas sector. Business Strategy and the Environment, 2020, 29(8): 3509-3525.

[2] Gutierrez-Gutierrez L, Barrales-Molina V, and Fernandez-Giordano M, et al. Six Sigma for dynamic capabilities development: becoming more flexible organizations. International Journal of Lean Six Sigma, 2020, 11(1):35-56.

[3] Zhao Xiaoyu, Gao Yuntei, Sun Men. Organizational flexibility of manufacturing enterprises, dynamic service innovation capability and service. Science \& Technology Progress and Policy.2020, 37(15):62-69.

[4] Wang Jun, Jiang Ruochen, Cao Guangming. Effect of organization improvisation and organizational advantage: environmental uncertainty and organizational flexibility as moderators. Research on Economics and Management, 2017, 38(3):92-100.

[5] Linda Holbeche .The Agile Organization- How to Build an Innovative, Sustainable and Resilient Business. Kogan Page, 2015.

[6] Xhafa F, Kryvinska N, Gregus M. Models and management of elasticity and openness: towards flexible organizations. Global Journal of Flexible Systems Management, 2017, 18(1):1-2.

[7] Fewell, Jennifer H. Social Biomimicry: what do ants and bees tell us about organization in the natural world? Journal of Bioeconomics, 2015, 17(3):1-10.

[8] Telha A, Andrade N, Páscoa C, Tribolet J. Representing the attributes of an organizational position in business processes. Procedia Computer Science, 2015, 64:562-569.

[9] Zhang Zhijun. Research on flexible organizational process management of aerospace model projects based on critical chain technology. Science and Technology management Research, 2020, 40(24):237-244.

[10] Shen Ao, Jiang Xu. Research on the impact of strategic flexibility on new product performance under dynamic environment. Science of Science and Management of S. \& T, 2019, 40(1):124-136.

[11] Dai Y, Goodale J C, Byun G, Ding F. Strategic Flexibility in new high technology ventures [J]. Journal of Management Studies, 2018, 55(2):265-294.

[12] Yang J, Zhang F, Jiang X, Sun, W. Strategic flexibility, green management, and firm competitiveness in an emerging economy . Technological Forecasting \& Social Change, 2015, 101:347-356.

[13] Liu Xiangyu, Li Xinjian, Wei Haibo. Research on the flexible organization establishment based on HRM strategic fit and dual flexibility__ A Longitudinal Case Study of Haier. Soft Science, 2018, 32(7):56-60.

[14] Kast B F, Rosenzweig J. Organization and management: a systems and contingency approach. McGraw-Hill Companies. 1985.

[15] Pugh D S, Hickson D J, Hinings C R. Writers on organizations. Penguin Books, 1982.

[16] Luthans F. Introduction to Management: A Contingency Approach. McGraw-Hill Book Company, 1976.

[17] Wright P M, Snell S A. Toward a unifying framework for exploring fit and flexibility in strategic human resource management. The Academy of Management Review, 1998, 23(4): 756-772.

[18] Verdu-Jover A J, Alos-Simo L, Gomez-Gras J M. Adaptive culture and product/service innovation outcomes. European Management Journal, 2017, 36(3):330-340.

[19] Zhou Guangwei. Research on industrial orientation of high-speed rail new town from the perspective of two industries integration. Market Weekly, 2020, 33(10):39-40.

[20] Allen C, Imrie R. Collaborative organizational forms: on communities, crowds, and new hybrids. Journal of Organization Design, 2018, 7(1): 11. 